\title{
Argyria caused by chronic ingestion of silver
}

\author{
Nathan A. Bracey MD PhD, Jonathan S. Zipursky MD, David N. Juurlink MD PhD
}

Cite as: CMAJ 2018 February 5;190:E139. doi: 10.1503/cmaj.171374

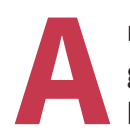

n 84-year-old woman was referred to our clinic with grey discolouration of her face. She had a history of hypertension that was managed with amlodipine and olmesartan. She reported that she had ingested an ionic silver solution $(1 \mathrm{mg} / \mathrm{mL})$, which she purchased from a naturopathic practitioner, every two to three months for the preceding 15 years as a remedy for various ailments.

On physical examination, the patient had a grey discolouration of her face, neck and conjunctivae (Figure 1). Laboratory investigations showed only an elevated serum concentration of silver (178.34 [reference range 0 to 1.86] nmol/L) and a random urine silver/creatinine ratio of 605 (reference range 0 to 77.5) $\mathrm{ng} / \mathrm{g}$.

The patient was counselled to discontinue use of the solution; however, no visible improvement was noted at two-month follow-up. She was referred to dermatology for consideration of laser skin treatment.

Argyria refers to benign grey discolouration of the skin that occurs in sun-exposed areas because of exposure to silver. Skin discolouration can result from other systemic diseases and medications (Appendix 1, available at www.cmaj.ca/lookup/ suppl/doi:10.1503/cmaj.171374/-/DC1). Acute exposure to silver can cause suppression of bone marrow, hepatotoxicity and acute tubular necrosis; however, chronic exposure typically only leads to altered pigmentation of the skin. ${ }^{1}$ Ingested silver particles are ionized in the stomach, transported to the skin and photoreduced where they collocate with selenium to impart a blue/grey discolouration. ${ }^{2}$ Management is limited to discontinuation of the use of silver and minimization of exposure to the sun, athough there has been interest recently in laser therapies. ${ }^{3}$ There is no role for chelation.

Silver-containing solutions have been used by alternative medicine practitioners as antimicrobial therapies. In Canada, they can be sold with homeopathic medicine numbers that are issued and reviewed by Health Canada, which implies that they are recognized as safe and effective. Despite this, silver taken orally has no proven utility for any medical condition. Physicians should be aware that silver-containing solutions are available in Canada and that patients consuming them are at risk of argyria.

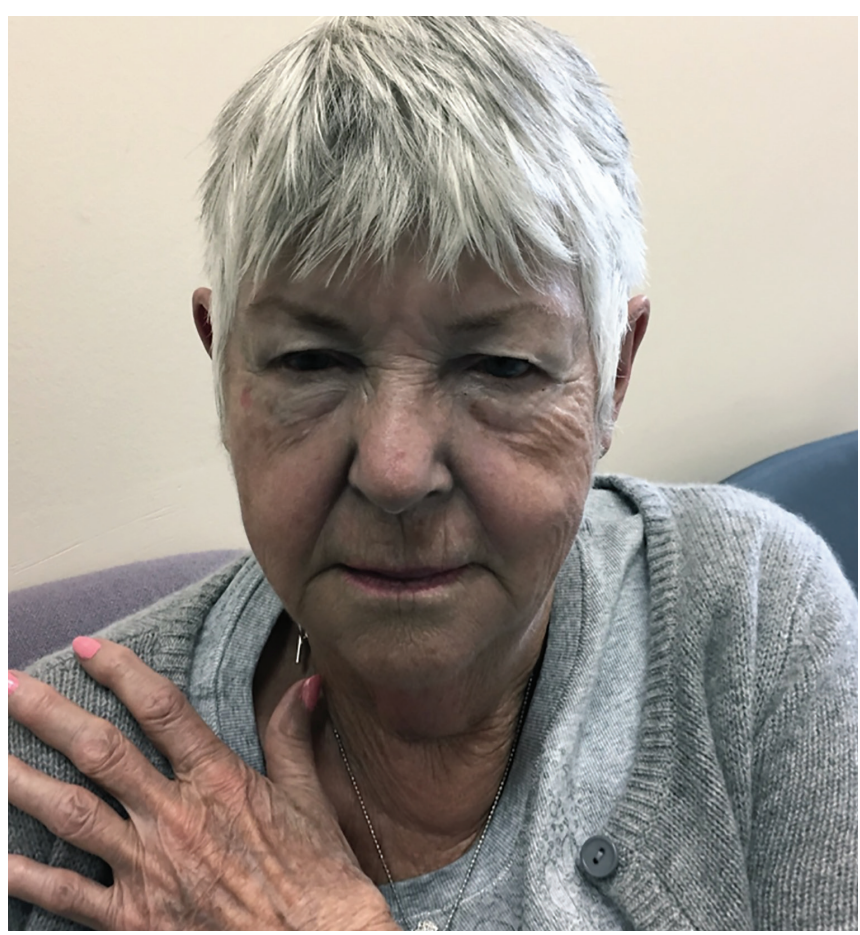

Figure 1: Grey discolouration of the face in an 84-year-old woman with argyria.

\section{References}

1. Lai Becker MW, Burns MM. Silver. In: Hoffman RS, Howland MA, Lewin NA, et al., editors. Goldfrank's toxicological emergencies. 10th ed. New York: McGrawHill; 2015:1271-5.

2. Liu J, Wang Z, Liu FD, et al. Chemical transformations of nanosilver in biological environments. ACS Nano 2012;6:9887-99.

3. Griffith RD, Simmons BJ, Bray FN, et al. $1064 \mathrm{~nm}$ Q-switched Nd:YAG laser for the treatment of Argyria: a systematic review. J Eur Acad Dermatol Venereol 2015;29:2100-3.

\section{Competing interests: None declared.}

This article has been peer reviewed.

The authors have obtained patient consent.

Affiliation: Department of Medicine, Sunnybrook Health Sciences Centre, Toronto Ont.

Correspondence to: Nathan Bracey, nathan.bracey@mail.utoronto.ca 